Asians in Birmingham, which show that $\mathrm{BCG}$ vaccination confers useful protection against tuberculous disease.

A discussion about why BCG in the newborn should be more effective than vaccination in older children and adults is outside the scope of this letter. One possibility, however, is that children given BCG vaccination soon after birth or at birth are not exposed sufficiently long to environmental factors which might mitigate the effect of BCG vaccination. For example, in areas where infection with atypical mycobacteria is common, such an infection before vaccination might provide a level of immunity comparable with that provided by BCG. This naturally acquired immunity might nullify or even oppose the effect of BCG vaccination.'

Dr Singh's results are in accordance with previous studies showing that tuberculin skin sensitivity induced by BCG vaccination diminishes with time. However, his interpretation of the results may be at fault because he makes the commonly made but erroneous assumption that tuberculin sensitivity equates with immunity against tuberculous disease. Indeed, there is evidence suggesting the absence of an association between tuberculin sensitivity and immunity. ${ }^{2}$ Although it is likely that the protection conferred by BCG wanes with time after vaccination, it does not necessarily diminish at the same rate as tuberculin sensitivity.

In his study, Dr Singh found that $6 \cdot 7 \%(6 / 90)$ of his vaccinated subjects developed tuberculous disease by 18 months after vaccination. These results presented in isolation do not argue against the efficacy of $\mathrm{BCG}$ vaccination. If, for example, the incidence of tuberculosis in unvaccinated subjects in the same community over a comparable period was significantly higher than that in the vaccinated group it would strongly suggest that BCG was exerting a protective effect.

Similarly Dr Singh quotes a study in which $73.7 \%$ of proved cases of tuberculosis in a population had received BCG vaccination, and cites this as evidence against the efficacy of the vaccine. Again, this information alone is inadequate to reach any conclusion about the efficacy of BCG. In his quoted example, if $90 \%$ of the total population had been vaccinated, the estimated protective efficacy of the vaccine would still be $68.9 \%$-a level sufficient to justify its continued use. This result is difficult to grasp intuitively but can be better understood by reference to the paper by Smith. ${ }^{3}$

We firmly believe that routine BCG vaccination of the newborn and infants is a valuable preventative measure in communities where there is a high incidence of tuberculous disease.

\footnotetext{
References

1 Anonymous. Is BCG vaccination effective? Tubercle 1981;62: 219-21.

2 Tidjani O, Amedome A, ten Dam HG. The protective effect of BCG vaccination of the newborn against childhood tuberculosis in an African community. Tubercle 1986;67:269-81.
}

${ }^{3}$ Smith PG. Retrospective assessment of the effectiveness of BCG vaccination against tuberculosis using the case-control method. Tubercle 1982;62:23-35.

\section{Incidence of zinc and copper deficiency in Japan}

Sir,

This correspondence is concerned with the report by Shaw ${ }^{1}$ in which copper concentrations of infant formulas were cited from data by Lönnerdal et al as being $60 \mu \mathrm{g} / \mathrm{l}$ in Japan and $120-680 \mu \mathrm{g} / \mathrm{l}$ in other countries. ${ }^{2}$

In 1983, we sent questionnaires to 662 hospitals concerning zinc and copper deficiency from 1978-83. Three hundred and thirty five (51\%) replied, of which 86 had treated children with these deficiencies. Further detailed answers were obtained from 40 out of these 86 hospitals $(47 \%)$; deficiency for zinc was recorded in 76 cases and for copper, 11 cases. For those with zinc deficiency, 43 were under 6 months of age and 14 were aged 6 months to 1 year. Thus most of the patients $(57 / 76,75 \%)$ were under 1 year of age. Of the 76 patients, 17 were premature infants, 33 had intractable diarrhoea, 12 were on parenteral nutrition, two had inherited acrodermatitis enteropatica, and 12 had other complaints. Only two premature infants and none with intractable diarrhoea were fed breast milk. Of those with copper deficiency, two were below 6 months of age and seven were aged 6 months to 1 year. Like the infants with zinc deficiency these infants were mostly $(9 / 11,82 \%)$ under 1 year of age. At the time of this survey, the contents of zinc and copper in commercial formulas were $0 \cdot 81-1.82 \mathrm{mg} / \mathrm{l}$ and $30-80 \mu \mathrm{g} / \mathrm{l}$, respectively, as reported by Lönnerdal et al. ${ }^{2}$ Since 1984, when the Japanese government accepted the addition of zinc and copper to infant formulas up to the concentrations recommended by the Food and Agricultural Organisation/ World Health Organisation $(3.2 \mathrm{mg} / \mathrm{l}$ zinc, $300 \mu \mathrm{g} / \mathrm{l}$ copper), the number of cases of zinc and copper deficiency has been dramatically reduced. Only five cases of zinc deficiency and no cases of copper deficiency have been recorded in the last three years among the same 40 hospitals concerned with the first survey.

\section{References}

1 Shaw JCL. Copper deficiency and non-accidental injury. Arch Dis Child 1988;63:448-55.

${ }^{2}$ Lönnerdal B, Keen $\mathrm{CL}$, Ohtake M, Tamura T. Iron, zinc, copper, and manganese in infant formulas. Am J Dis Child $1983 ; 137: 433-7$.

I Matsuda and A Higash Department of Pediatrics, Kumamoto University Medical School, Kumamoto 860, Japan 